Meta

Journal des traducteurs

Translators' Journal

\title{
Man/Machine Interface in Translation and Terminology
}

\section{Barbara Moser-Mercer}

Volume 32, numéro 2, juin 1987

Vers l'an 2000. La terminotique, bilan et prospectives

Objectives: Year 2000 Terminotics. State of the Art, Prospects for the

Future

URI : https://id.erudit.org/iderudit/003632ar

DOI : https://doi.org/10.7202/003632ar

Aller au sommaire du numéro

Éditeur(s)

Les Presses de l'Université de Montréal

ISSN

0026-0452 (imprimé)

1492-1421 (numérique)

Découvrir la revue

Citer cet article

Moser-Mercer, B. (1987). Man/Machine Interface in Translation and

Terminology. Meta, 32(2), 156-163. https://doi.org/10.7202/003632ar d'utilisation que vous pouvez consulter en ligne.

https://apropos.erudit.org/fr/usagers/politique-dutilisation/ 


\title{
MAN/MACHINE INTERFACE IN TRANSLATION AND TERMINOLOGY
}

\author{
BARBARA MOSER-MERCER \\ Monterey Institute of International Studies, \\ Monterey, California, USA
}

\section{INTRODUCTION}

Who would ever think of a "man/automobile interface" to describe driving a car? The individual components of a car might well be rather complex, its functions however are simple in comparison to an equally expensive computer. Furthermore, it is abundantly clear that the driver has to come along in order to monitor and control the car's functions and that he can interrupt the process or modify the course at any time. Thus, man has complete control over the automobile.

Loaded with the right programs, a computer can be made to carry out any intellectual task, provided it has been formalized. Depending on the program, a computer will process all kinds of data. Only those users who are also programmers and who know the system can think of total control. When programs are interactive, interrupting themselves to request information from the user, only to continue after the necessary data have been supplied, the "interface" then becomes intriguing. The openness of the system allows the user some measure of control (Nake 1984).

This article will cover the various types of man/machine interface in terminology and translation. Translators and terminologists are not forced into total adaptation or submission, but are being challenged to rethink their work process. One should, however, not dismiss the dangers of automation entirely, as Mahr (1984) rightly points out :

Computers destroy jobs, enforce a kind of standardization which leads to inflexibility, they create new dependencies and reduce human contacts. Automation is a spiral. Human work is first assisted by the computer, then, by way of rationalization, it is replaced by a computer system. This allows for new possibilities, new services are conceivable which did not exist before, and man makes use of them. Automation has been unleashed... We are replaced by computers and the process is irreversible, once we have embarked upon it.

If we are to interpret correctly the translation world's cry for access to terminology data banks, for text processing systems geared to the needs of the translator, then the profession has already embarked on the course of automation. The fact that we already have a number of major and smaller terminology data banks, that language services of large corporations and organizations are in the process of installing, or have already installed, machine translation systems, that many free-lance translators are working on their own PC or are about to throw themselves into the dilemma of choosing the right system for their needs, is proof enough that the spiral of automation is turning rapidly. Taking stock of the present situation, analyzing the conceptual underpinnings and getting a head start on acquiring information on the future course of automation may best prevent translators and terminologists from having their professional world "fully wired" for them. 


\section{ORGANIZATIONAL ASPECTS AND MACHINE ASSISTANCE : DEFINING THE INTERFACE}

An outline of MT- and MAT-systems lends greater clarity to the various types of man/machine interfaces. This is not the place to discuss the merits and shortcomings of any one system on the market, nor to provide a qualitative comparison between them. The categorization is simply intended to allow for a better analysis of the man $/ \mathrm{machine}$ interface.

Characteristic of the first two categories, batch systems and interactive MTsystems, is a drastic departure from the way a human translator organizes his work. While the human translator is free to choose the way he will approach the translation of a particular text, often varying his approach according to text-type and time constraints, MT pressures him into a given mold and any departure from the given will result in loss of time and quality.

\subsection{BATCH SYSTEMS}

These are understood to be MT systems that get by with a minimum of human intervention. In most cases the work of the translator is confined to pre- and post-editing of the text, while analysis of the source language text, transfer and synthesis of the target language text are done in a fully automatic process. Depending on the type of system, the work of up-dating the machine dictionary still falls within the scope of the translator's tasks. In other words, the translator exerts some control over a part of the system's data, primarily the lexical, but not over the grammatical and syntactical rules, while the algorithms, that is the instructions for applying these rules, are normally beyond his influence.

This raises questions of great importance, particularly as pertains to the design of a computer system. At what points is the user given access to the machine, and how is this access organized? Which parts remain inaccessible to the user, and what information is closed to him ? Answering these questions presupposes that the system designer knows the needs and behavior of the future user. That, however, is usually not the case, and so leaves only a thin pool of past experience to help guide the design. Typical problems have been recognized and need to be avoided :

The peephole effect - the terminal is like a peephole into a large ballroom. The user lacks the wide-angle perspective needed to gain an overall view.

The concrete effect - the user has the impression he has to conform to the computer, which is set and made of concrete (Hiltz and Turoff 1978).

Such phenomena can be seen especially with batch systems since the translator's work, apart from dictionary editing, is limited to purely mechanical tasks and the translator is even forced to correct mistakes whose origins are entirely alien to him. The translator must thus become a part of the machine, which then presupposes that he is submissive, accepts the machine and trusts it. The alienation is complete. The mystification of the machine total.

Does this mean that the computer has become an unassailable authority to which the translator has to conform or else categorically reject at the risk of losing his job ? A brief look back into the history of automation in other professions may well suggest such a conclusion. Our profession, however, is in a fortunate position to learn from recent experience and prevent history from repeating itself. Though the present trend in the profession is toward categorically rejecting MT, it would be well to bear in mind that the reasons for this rejection are to be found principally in the translator's lack of information about or access to the MT system, the absence of practicing translators in the development of MT systems, and the lack of understanding of the human translation process on the part of system developers. These deficiencies cannot be eliminated 
overnight, but concerted efforts to educate and enlighten, starting in the training of translators and then continued in the professional associations, are one promising way of overcoming the dearth of information on both sides. This also helps to establish a basis of trust and a positive climate of cooperation in which system developers take cognizance of the demands of the translator and translators, as an informed professional body, exercise influence on the development of MT systems. In so doing neither side can cling to the status quo. System developers are called upon to design MT systems that are user-friendly and grounded in the overall translation process, though with the abundance of still unresolved software problems this is often viewed as an inordinate demand. By the same token, translators have to develop a broader perspective for the changes in the translation environment. The incorporation of data processing into translating is inexorable. It is in part up to the translator, by means of improved information, to shape this development rather than be shaped by it (Moser-Mercer 1985a).

\subsection{INTERACTIVE SYSTEMS}

The borderline between interactive systems and computer-assisted translation is a fluid one, and many subject specialists would probably include all interactive systems in the category of computer-assisted translation or electronic aids. But the distinction is useful since an interactive system does deliver a rough translation, which of course one could not claim of, e.g., terminology data banks or text processing systems, which fall in the category of electronic aids to translation.

Just as a batch system does, an interactive system works with data and algorithms and carries out analysis, transfer and synthesis. However, in contrast to the batch system, the translator for the most part controls which data are supplied to the algorithm. Depending on the degree of difficulty of the SL-sentence, the MT program requires from the translator information on grammatical structures and terminology. Thus, on the display terminal the translator is shown different grammatical and terminological options, from which he selects on the basis of an analysis of the SL-sentence. Questions from the system usually concern SL-analysis, terminology or TL-synthesis. The more the translator is familiar with the system and the better he has organized and edited his machine dictionaries, the fewer interactions there will be, which means the translation process is speeded up significantly. A more detailed discussion of terminological interaction might illustrate this point.

Example from a source language text :

This office automation system allows for organizing your documents in directories, drawers and files.

Question : Select correct equivalent for "file"

a) Akte

b) Nagelfeile

c) Feile

d) Datei

etc.

This example demands a more detailed explanation of the organizational sequence of the translation process in interactive MT-systems. For reasons of economy the number of interactions should be kept to a minimum. This applies especially to interactions concerning terminology.

The sequence of work in an interactive MT-system differs substantially from that of human translation. Starting point is the storage of the source language text in the computer. The next step consists in the terminological analysis of the text. For this the 
relevant technical and general language dictionaries stored in the computer are used to conduct a terminological search. The dictionaries are arranged in order of priority. In a text on letter-quality printers, this sequence might look something like this :1) glossary on letter-quality printers, 2) glossary on printers, 3) data processing dictionary, 4) technical dictionary, 5) general dictionary. During the analysis the terminological units of the SL-text are marked off by the computer program and compared with entries in the machine dictionaries, whereby glossary 1) is searched first and dictionary 5) last. If an equivalent appears in more than one dictionary, the translator could, for example, choose to include all equivalents in his new dictionary, generated specially for this text on letter-quality printers, or only the equivalent from the glossary of first priority.

This terminological analysis is a fully automatic process and provides the dictionary specific to the text to be translated. At the same time a KWIC list (keywords in context list) and a list of terms not found in the machine dictionaries may be generated. The KWIC list contains all terms found during analysis along with all the contexts pertaining to them and thus allows the translator to edit efficiently a document dictionary. Returning to the above example with the term "file", if we know that this sentence is taken from a text on office systems, then the translator would consult the KWIC list to see how often and in what contexts "file" occurs in the SL-text. If he determines that "file" in this text should always be translated with "Datei", then all other equivalents can be deleted from the document dictionary or masked (so that the system no longer recognizes them), and this would eliminate any interaction during the translation process since there would no longer be any terminological choice for the computer. Also the translator will normally add to his text dictionary by accessing traditional resources such as printed dictionaries and glossaries, relevant literature or terminology data banks to search equivalents not found during analysis.

Thus we see that all the terminology work has to be done before the actual translating begins. In the process the translator acquires a new task, as he is largely responsible for managing and updating terminology in the machine dictionaries. The extent to which he bears sole responsibility naturally depends on the organizational circumstances in the workplace. In a large language service someone usually carries the final responsibility for administering the machine dictionaries. Yet this does not remove the translator from his work as terminologist. In a larger translation project in which several translators work on one text, one translator can take on this stage of text dictionary generation on his own, even if he does not subsequently take part in the translating.

In the course of automation, then, an "assembly line effect" can result as well. The translation process, which for the human translator is a continuum, is divided up. This can often result in the peephole effect mentioned above. To avoid this kind of fragmentation it would be wise in such a situation to select a project director who can be responsible for the terminology work but supervises the overall project up to revision and printing so as to maintain an overview of the whole.

The above suggests that no interactive system will work without the human translator. But no MT-system is perfect and the feedback from the translator/user is one of the most important sources of information for system developers and programmers. Interactive systems with their greater "transparency" of software and necessarily close collaboration between translator and system afford interested translators numerous opportunities to turn their translation experience into software improvements. The more unambiguously a system error can be classified the more likely it can be eliminated.

\subsection{ELECTRONIC AIDS}

Under this comprehensive term a wide range of resources have been developed in recent years, their common aim being electronic support for the human translation pro- 
cess. It is thus a matter of mechanizing and automating what is tedious and timeconsuming routine work and giving the translator more time for the creative part of the process.

These resources can be divided into three categories : text processing, terminology, and documentation.

\subsubsection{Text processing}

Text processing devices are ideal for translation because they spare us from the rewriting of several drafts since only the final copy need be printed out, and they facilitate corrections. Recent developments in the software field also provide for automatic correction of orthography, grammar and syntax as well as the storage and recall of electronic dictionaries.

\subsubsection{Terminology}

This includes all developments of electronic storage and recall of terminological data. The spectrum here extends from the simple file extension for address lists, which can be readily turned into an electronic card index, to the fully developed terminology data bank. The electronic "cousins" of our traditional paper dictionaries will in future play a major role as well.

The next, and more comprehensive, solution is offered by mini-data banks (see Baudot, Clas and Gross 1981, as well as Gouadec and LeMeur 1984). These are terminology data banks where subject fields are usually strictly defined and the number of language pairs is limited. This software usually runs on microcomputers. The available functions, such as record layout, search of records according to various categories (alphabetically, according to subject field, descriptors, etc.), the parsing of the indicated expression and breaking it down into its components with a subsequent search for these components, the printing of subject field wordlists, etc., greatly resemble those of the large terminology data banks. But because the memory capacity of microcomputers and personal computers is (still) limited, the volume of the data collection faces limits (storage of approx. 10000 to 15000 terms).

Certainly the most well-known are the large terminology data banks such as EURODICAUTOM, TERMIUM, TEAM, etc. With regard to the language requirements of the institutions administering them, these data banks have a much more extensive data collection (several hundred thousands of terms) in various languages and many subject fields. This naturally entails a certain unwieldiness in data acquisition and updating of the data base, which especially of late has prompted a call for more decentralized, smaller and more specialized data banks.

\subsubsection{Documentation}

Screening publications (both in paper and electronic form) for new terminology as well as filing translations electronically need not be the privilege of translators in large translation services. The free-lance translator can access databases of large language services and any other public database as well.

Whenever dictionaries, glossaries, card files and termbanks do not offer the needed responses, every responsible translator will turn to comparative reading of technical publications. But not every translator has a well-stocked library within reach. A terminal and a telecommunication package are all he needs to access databases at home and abroad (in addition to completing the required paperwork). He must, however, learn to understand the natural language in which the database search terms are expressed and correctly formulate his queries (Moser-Mercer 1985b). Still, databases open up a whole new world of useful information to the translator and can become an invaluable source of terminology (Brace 1981, INFOTERM 1985). 


\section{INTERACTION OR CONFRONTATION}

The needs and behavior of MT-users (including all professionals in the field of translation and terminology) have not yet been analyzed sufficiently, much less defined conclusively. For some, the trials and tribulations of daily work on the computer do not amount to a significant "technological breakthrough" in the profession, others view the computer with mixed feelings of fear, distrust, modest acceptance, and often as a good scapegoat if a translation job fails, and there are those for whom the computer has become as indispensible a tool as typewriters, dictaphones and card files were before.

Unless they are free-lance professionals and do not have to fear competitive pressure, the salaried professional has little say when it comes to automating his work environment. Yet the success of any system depends heavily on the user's acceptance. Here we might return to Mahr's (1984) statement about the long-term effects of automation. While system designers in MT and MAT have so far justifiably concentrated all their efforts on the linguistic aspects of MT-systems, psychological factors were usually relegated to a time when all other issues will have been solved. After 30 years of research in this area it has become quite obvious that the linguistic issues involved are much more complex and do not always lend themselves to elegant and quick solutions. The psychology of the user, however, cannot be further neglected. The entire profession is undergoing significant changes, as a cursory review of ASLIB-proceedings would undoubtedly reveal, and system designers need to pay more attention to the translator and terminologist as computer users on the one hand, and the integration of and communication among different types of systems, such as MT-systems, termbanks and expert systems.

\subsection{PSYCHOLOGICAL FACTORS}

So far the psychological needs and behavior of MT-users have received very little research attention. But we can draw certain analogies from the investigations of human factors in computer users in general. I have already mentioned the peephole-effect and the concrete-effect. Also worthy of mention is computer-anxiety or technophobia, the computer user's fear of "paralyzing" the machine or breaking something. The bully effect occurs when the immediate responses of the computer pressure the user into feeding new data, that is responding as quickly as the computer does. Whenever the user receives more information than he needs or can handle at any one time he may become the victim of the clutter-effect; as he is offered too many options to choose from he becomes paralyzed and unable to select any option (Hiltz and Turoff 1978).

\subsection{PHYSICAL FACTORS}

Quite often, a stroll to the local library or sifting through magazines provides a welcome break in the translator's concentration on the text and his predominantly sedentary job. Once all data (from MT-program to data received via modem from data banks) are available on screen, there will be no need for him to get up from his chair. As with fanatical hackers, his eyes may be glued to the screen all day long, and it takes months for him to discover that headaches, flickering in front of his eyes and tense muscles are the price he is paying for automation. Because of time pressure and pending deadlines computer novices in particular tend to overlook a basic rule : 15 minutes of abstinence from the screen for every hour spent in front of it.

\subsection{OPERATIONAL FACTORS}

As outlined in the discussion of batch and interactive systems, MT requires the translator to streamline his translation process. Whereas in human translation the translation process can be determined more or less freely by the translator himself, MT 
forces him into a predetermined mold. All terminology and dictionary work must be taken care of up front, because without these data the system will function only poorly or not at all. Frequently, however, the best terminological solution develops in the course of translating a particular text. (Though software-engineers have made provision for that, too. Text processing systems will most often feature a search/replace function, with which incorrect or unsuitable expressions can be replaced throughout the text at the touch of a key!)

Accessing remote databanks is usually rather expensive and the translator will thus have to collect all terminological queries and search the termbank in one "sitting", unsually under great time pressure since every minute of search time adds to the bill.

\subsection{FRAGMENTATION OF THE WORK PROCESS}

Batch systems, where translators are relegated to pre- and post-editing (if they are called upon to do the job at all) make the fragmentation of the translation process particularly obvious. Without an understanding of the MT-software, a translator has to correct mistakes that differ radically from those occurring in human translation. The fact that a particular type of mistake tends to recur throughout the batch-output often creates a feeling of impotence and anger in the translator. Having been limited to completing the non-creative phases of the translation process just adds to his feelings of alienation. Interactive systems have an advantage here, as the translator can edit the machine dictionary and MT-output throughout the translation process and thus has a greater degree of control.

Splitting up the translation process into terminology work and translation work proper may have an assembly-line effect on the translator. Since the number of trained terminologists is still relatively small and given the fact that language services often cannot justify hiring a professional terminologist or do not recognize the need for one, the task of maintaining machine dictionaries falls to the translator, who frequently lacks adequate terminological training. The integration of translation, terminology, and machine translation training in translation schools then becomes a prerequisite for the successful installation of MT-systems (Moser-Mercer 1985a).

\subsection{FORMALIZING LINGUISTIC INFORMATION}

What the human translator formulates correctly by intuition, requires formalization in machine translation. This is particularly true for dictionary editing, where exact coding of terminological and lexicographical data is a prerequisite for the proper functioning of the system. Few translation students dispose of the requisite formal grammatical knowledge, however. For the translator to provide useful feedback on software bugs he must recognize mistakes correctly (whether they occur in the analysis, transfer, or synthesis phase or whether they are a result of incorrect coding in the dictionary), and describe them in correct linguistic terms, so that programmers can make the necessary adjustments in the software. Programmers are not translators. Their task is to transform recognized processes into algorithms, that is to formalize processes. Here the translator's expertise can be of invaluable help.

\section{PERSPECTIVES FOR THE FUTURE}

With the introduction of new software the translator will continue to be confronted with the new and unknown. This will require a great deal of flexibility of him. For the translator to take an active role in improving MT-software and the man/ machine interface means that he continues to preserve a large degree of control over his work. In the freelance market the decision to automate still lies with the translator, the only pressures there stemming from maintaining profitability and a competitive edge. 
With the spiral of automation turning as quickly as it does, preserving these two may require some degree of automation soon. The salaried translator must accept automation - or leave the job.

Particularly in the area of machine aids to translation we will see a colorful array of software. Grammar checkers, spell checkers, electronic versions of familiar paper dictionaries and more frequent updates of reference works, termbank software for microcomputers allowing for regular exchange of terminology among freelancers, are but a few examples of how the translator's work environment will change. The possibilities seem endless. The reaction in the profession ought not to be characterized by categorical rejection, but by the translators' ability to distinguish clearly between positive and negative developments.

Martin Kay's (1980) comment could well be adopted as a guideline for the future :

A computer is a device that can be used to magnify human productivity. Properly used, it does not dehumanize by imposing its own Orwellian stamp on the products of the human spirit and the dignity of human labor but, by taking over what is mechanical and routine, it frees human beings for what is essentially human. Translation is a fine and exacting art, but there is much about it that is mechanical and routine and, if this were given over to a machine, the productivity of the translator would not only be magnified but his work would become more rewarding, more exciting, more human. It is altogether right that we shoud look to the computer. Indeed, if the need for translation is as great as it is said to be, the computer is our only hope.

\section{BIBLIOGRAPHY}

ALPAC (1966) : Machines and Translation, Washington, D.C., NAS/NCRC.

BAUDOT, J, A. CLAS and M. GROSS (1981) : "Un modèle de mini-banque de terminologie bilingue", in $M E T A, 26-4$.

BRACE, G. (1981) : "On Using On-Line Databases for Help in Technical Translating", in : META, 26-1. GOETSCHALCKX, J. and L. ROLLING (1981) : Lexicography in the Electronic Age, Amsterdam/New York, North Holland Pub. Co.

GOUADEC, D. and A. LeMEUR (1984) : "Les micro-banques de terminologie - Instruments d'une pratique ; outils d'apprentissage - Le système TERM.X", in META, 24-4.

HILTZ, S.R. and M. TUROFF (1978) : The Network. Nation-Human Communication via Computer, New York, Addison-Wesley.

INFOTERM (1985) : Terminologie und benachbarte Gebiete : 1965-1985, Wien, Köln, Graz, Herman Böhlaufs Nachf.

KAY, Martin (1980) : The Proper Place of Men and Machines in Language Translation, Palo Alto, CA, Xerox Research Center.

KUSTERER, H. (1982) : "Textverarbeitung - nicht nur für den Grossbetrieb", in : Lebende Sprachen, $\mathrm{n}^{\circ} 2$.

MAHR, B. (1984) : "Die Herrschaft der Gebrauchsanweisung", in : Kursbuch Nr. 75, Computerkultur, March ; Berlin, Rotbuch Verlag.

META (special issue) (1981) : l'Informatique au service de la traduction, 26-1, Montréal, les Presses de l'Université de Montréal.

MOSER-MERCER, B. (1986) : "Terminology Training and Technology in California", in : INFOTERM. Proceedings. Second Infoterm Symposium. Networking in Terminology. Munchen/New York/London/ Paris, K.G. Saur.

MOSER-MERCER, B. (1985b) : "Machine Translation and Documentation", in : l'Informatique pour l'information et la documentation, Actes des Journées nationales de la documentation, Computer 85, Lausanne, Geneva, Groupe romand de l'Association suisse de documentation.

NAKE, F. (1984) : "Schnittstelle Mensch-Maschine", in : Kursbuch no 75, Computerkultur, March ; Berlin, Rotbuch Verlag.

SCHNEIDER, T. (1984) :"Problems Incorporated. Translation Management in an Industrial Environment", in : $M E T A, 29-4$.

SCHWENGLER, L.W. (1983) : "Einsatz von Textverarbeitungsanlagen in einem Sprachendienst der Industrie", in : Lebende Sprachen, $\mathrm{n}^{\circ} 3$. 